\title{
Core-shell magnetic particles obtained by seeded suspension polymerization of acrylic monomers
}

\author{
Jacira Aparecida Castanharo ${ }^{1}$, Ivana Lourenço de Mello Ferreira', Manoel Ribeiro da Silva ${ }^{2}$ \\ and Marcos Antonio da Silva Costa ${ }^{1 *}$ \\ ${ }^{1}$ Universidade do Estado do Rio de Janeiro - UERJ, Rio de Janeiro, RJ, Brasil \\ ${ }^{2}$ Universidade Federal de Itajubá - UNIFEI, Itajubá, MG, Brasil \\ *marcoscosta.iq.uerj@gmail.com
}

\begin{abstract}
Core-shell magnetic polymer particles were synthesized by seeded suspension polymerization. The core was made of poly(methyl methacrylate-co-divinylbenzene) and a mixture of magnetite, maghemite and goethite (P(MMA-co-DVB)-M). The shell was composed of poly(glycidyl methacrylate-co-divinylbenzene) (P(GMA-co-DVB)). These particles were characterized by infrared spectrometry (FTIR), thermal analysis (TG), scanning electron microscopy (SEM), dynamic light scattering (DLS) and vibrating sample magnetometry (VSM). The results showed the formation of core-shells with good magnetic properties $(\approx 7.1 \mathrm{emu} / \mathrm{g})$ and good thermal resistance $\left(\approx 300^{\circ} \mathrm{C}\right)$. The light scattering experiments showed that the particle size of these materials changed from 5-90 microns (core) to 5-120 microns (core-shell). Scanning electron microscopic images were useful to show the formation of P(GMA-co-DVB) shells on P(MMA-co-DVB)-M cores. The materials synthesized in this work have potential to be modified and employed in magnetic separation processes in the biotech and environmental fields.
\end{abstract}

Keywords: magnetic polymer microspheres, core-shell, seeded suspension polymerization, biopolymers.

\section{Introduction}

Core-shell magnetic polymer particles are typically prepared by a series of emulsion, dispersion or suspension polymerizations. Both core and shell domains can be composed of varied materials, including polymers, inorganic solids, and metals ${ }^{[1]}$. The core-shell model is becoming the most efficient way to use magnetic polymer particles as carriers and separators in the technological field. The magnetic nanoparticles can be shifted to the polymer core so they remain protected from the weather (e.g., oxidation) and to prevent leaching of nanoparticles during application, maintaining their magnetic properties during use cycles. The surface properties are obtained by coating, allowing the integration of various functionalities to the final polymer particles. The core-shell synthesis is performed consecutively or sequenced in the presence of different monomers, where these seeded particles can be prepared in more than one polymerization stage or a single stage (in situ ${ }^{[2,3]}$. Pinto et al. ${ }^{[4]}$ synthetized core-shell polymer particles combined with suspension-emulsion polymerizations using styrene and employed lipase B from Candida Antarctica as support for immobilization. They described the performance of the biocatalysts as a function of the specific area, pore volume and average pore diameter of the supports. They observed that the average pore sizes did not affect the enzymatic activities in the analyzed range of pore sizes. They also observed that the increase of the specific area (and of the pore volume) led to higher enzyme loadings as well as an increase in the esterification activity. Besteti et al. ${ }^{[5]}$ also combined suspension-emulsion polymerizations to produce polymer supports using styrene, methyl methacrylate, and cardanol as monomers. They reported that the obtained polymer particles presented the characteristic core-shell particle structure, with specific areas and average pore sizes. They also showed that the particles could be used successfully for immobilization of CALB, leading to immobilization efficiencies and enzyme activities better than the ones obtained with Accurel MP 1000 (commercial support for the immobilization of enzymes).

Ribeiro et al. ${ }^{[6]}$ produced core-shell particles by seeded suspension polymerization by using polystyrene (PS) as polymer core, or seed, and methyl methacrylate (MMA) as the shell forming monomer. The TEM measurements revealed that the core-shell morphology consisted of PMMA clusters dispersed in the PS matrix. The synthesized core-shell particles presented enhanced chemical resistance to cyclohexane compared to PS. Despite extensive work on the seeded polymerization technique, these materials do not have magnetic properties. Moreover, only one paper on magnetic core-shells synthesized by seeded suspension polymerization exists ${ }^{[7]}$. In this work ${ }^{[7]}$, magnetic polymeric microspheres based on styrene (STY) and divinylbenzene (DVB) were synthesized in two steps. The addition method and the swelling time were varied. All methods tested to form the poly(styrene-co-divinylbenzene) shell produced particles with diameter larger than the core. The best results obtained used 48 hours of core swelling at $10^{\circ} \mathrm{C}$. Therefore, the objective of this study was to synthesize a magnetic polymer with core-shell morphology by suspension seeded 
polymerization based on MMA (core) and GMA (shell) with lower swelling time and at room temperature. This material could have advantages, such as biocompatibility, protection of magnetic material within the core and shell characteristics that can be chemically modified to obtain tailor-made magnetic polymeric particles. For example, the epoxide group of the poly (glycidyl methacrylate) shell may undergo amination reaction for the introduction of amine groups, producing a material with application to the immunocapture of b-amyloid peptides ${ }^{[8]}$, immunomagnetic separation of bone marrow cells ${ }^{[9]}$, capture of epithelial cancer cells ${ }^{[10]}$, etc. In the environmental area, these same materials could be used for removal of heavy metals ${ }^{[1]}$ and dyes ${ }^{[12]}$ from aqueous media.

\section{Materials and Methods}

\subsection{Materials}

All monomers were commercial grade. Divinylbenzene (DVB) (Nitriflex, Rio de Janeiro, Brazil), methyl methacrylate (MMA) (Lanxess, Rio de Janeiro, Brasil) and glicidyl metacrylate (GMA) (Sigma, St. Louis, USA) were used as received. 2-2'-azo-bis-isobutyronitrile (AIBN) (Migquimica, São Paulo, Brazil) was used after purification in methanol PA (B’Herzog, Rio de Janeiro, Brazil). Poly(vinyl alcohol) (PVA 224) (Kuraray, Tokyo, Japan), sodium chloride ( $\mathrm{NaCl}$ ) (Vetec, Rio de Janeiro, Brazil), sodium dodecyl sulfate (SDS) (B'Herzog, Rio de Janeiro, Brazil), n-heptane (Vetec, Rio de Janeiro, Brazil) and toluene (Vetec, Rio de Janeiro, Brazil) were also used as received. The magnetic material was composed of magnetite, maghemite and goethite, as described in our previous paper ${ }^{[13]}$.

\subsection{Core-shell synthesis}

\subsubsection{First step}

The poly(methyl methacrylate-co-divinylbenzene)magnetic core (P(MMA-co-DVB)-M) was synthesized as described in our previous paper ${ }^{[13]}$. The organic phase (OP) was composed of 0.3 total mols $(0.27$ mols of MMA and 0.03 mols of DVB), $5 \%$ m.m. magnetic material, n-heptane (100\% degree of dilution) and $2 \%$ m.m. AIBN. The aqueous phase (AP) was composed of $1 \%$ m.v. PVA and $1 \%$ m.v. NaCl. We performed a semi suspension of $\mathrm{OP}$ at $50{ }^{\circ} \mathrm{C}$ during 30 minutes at $700 \mathrm{rpm}$. After this step, the $\mathrm{OP}$ was added to the aqueous phase (volume ratio $\mathrm{OP}: \mathrm{AP}=1: 4$ ) and the suspension polymerization was conducted at $80^{\circ} \mathrm{C}$ for $4 \mathrm{~h}$.

\subsubsection{Second step}

The shell was obtained by seeded polymerization, adapted from the literature ${ }^{[14,15]}$. This involved placing $0.5 \mathrm{~g}$ of the core (or seed) in a $500 \mathrm{~mL}$ three-necked flask. Under stirring (200 rpm), the aqueous phase of the coating, containing PVA at $1 \%$ m.v. and SDS, was added to the reaction system. Next, half of the organic phase of the coating (GMA:DVB = 9:1) was added dropwise. The swelling occurred at room temperature for $1 \mathrm{~h}, 12 \mathrm{~h}$ or $24 \mathrm{~h}$. After this time, the second part of the OPC was mixed with $1 \% \mathrm{~m} . \mathrm{m}$. AIBN and added dropwise to the reaction. The suspension polymerization occurred for $4 \mathrm{~h}$, at $70{ }^{\circ} \mathrm{C}$, under stirring at $600 \mathrm{rpm}$. All solutions remained an ultrasonic bath for
15 minutes before being used. We analyzed the swelling time, surfactant concentration (without sodium dodecyl sulfate - WSDS, with sodium dodecyl sulfate below the critical micelle concentration - BCMC and above it - ACMC) and mass ratios of seeds in shell monomers of 1:5 and 1:10. All the synthesized materials were purified with a Soxhlet extractor, first with toluene and then with n-heptane, and dried at $60{ }^{\circ} \mathrm{C}$.

\subsection{Instrumentation and characterization}

The composition of the core-shells was analyzed by the FTIR ATR method (PerkinElmer Spectrum One spectrometer) in the range between $4000 \mathrm{~cm}^{-1}$ and $550 \mathrm{~cm}^{-1}$, where each spectrum was scanned at the resolution of $4 \mathrm{~cm}^{-1}$. The VSM measurements (Lake Shore 7400 magnetometer) were performed on $0.05 \mathrm{~g}$ of sample, with a magnetic field between $\pm 12 \mathrm{KG}$, at room temperature, during 10 minutes. The morphology of the material was analyzed by SEM (FEI Inspect 550). Previously, the sample was placed on conductive tape and coated with a layer of gold to increase conductivity and protect against localized heating. The coated sample was loaded in the equipment to allow interaction with secondary electrons, under high vacuum and acceleration voltage of $20 \mathrm{kV}$. The particle size distribution of the seeds (cores) and the core-shells was determined by laser light scattering (Malvern, Mastersizer 2000). The samples were placed in the analyzer's chamber containing a water and ethanol solution. The presence of a stirring system (1750 rpm) assured dispersion and homogenization of the particles in the medium. The samples were fed through the analyzer with the aid of a pump. The thermal degradation of the materials was checked by TG (TA Instruments, Q50 V6.4 Build 193), where about $10 \mathrm{mg}$ of sample was placed in a platinum dish and heated under a nitrogen atmosphere with a flow rate of $100 \mathrm{~mL} / \mathrm{min}$, from $50{ }^{\circ} \mathrm{C}$ to $650{ }^{\circ} \mathrm{C}$ at a rate of $10^{\circ} \mathrm{C} / \mathrm{min}$. The deviation of the tangent method for marking curves was used.

\section{Results and Discussion}

Figure 1 shows the electronic micrographs of the core by SEM (Figure 1a and 1b). The surface of the core has compact and shapeless structures (Figure 1b). It is possible to visualize small agglomerated spherical particles inside the larger microsphere (Figure 1a). These morphological differences between the external surface and interior of microspheres are common features of crosslinked macroporous polymers synthesized by suspension polymerization. It is known that the diluent-copolymer affinity modifies the nuclear chains and the internuclear ones as well, and the use of a nonsolvating diluent (heptane) has a tendency to produce large pores. The literature ${ }^{[16]}$ explains that the nongel porosity occurs through channels between various spherical gel particles with smaller size bonded together, forming a larger microsphere, so the polymer domains are present as compact and formless structures. This agglomeration of microspheres inside the beads can cause an opaque appearance because of these structures. The greater compactness of polymeric areas on the surface than inside the microspheres has been attributed to compression due to the interfacial tension between the 
organic phase and the aqueous phase during the suspension polymerization $^{[17]}$.

Figure 2 and Figure 3 show the SEM results of the core-shell microspheres. Generally, comparison of the core-shell surfaces (Figure 2b, 3b, 3d and 3f) with the core surface (Figure $1 b$ ) reveals differences. While the surface of the core is compacted and has no defined shape, the surfaces of the core-shells have varying shapes, such as a film distributed along the full extent of the microsphere with very small structures adhered to the surface, including the presence of some bubbles. In general it was possible to produce a uniform coating and control the shell thickness.
The high magnification SEM images provided information about the change of the microspheres' surfaces after the seeded polymerization process. This result is in accordance with the literature ${ }^{[1,15,18]}$. These surfaces are characteristic of non-porous shells. According to Lenzi et al. ${ }^{[19]}$, when the core used as seed is washed and dried, the result, after the seeded suspension polymerization, is polymer particles that coalesce, while the swollen suspension particles lose their compartmentalized character. Chaudhuri and Paria ${ }^{[1]}$ reported that these smooth surfaces as a coating can be obtained when the shell material is produced directly on the surface of the core by heterogeneous nucleation.

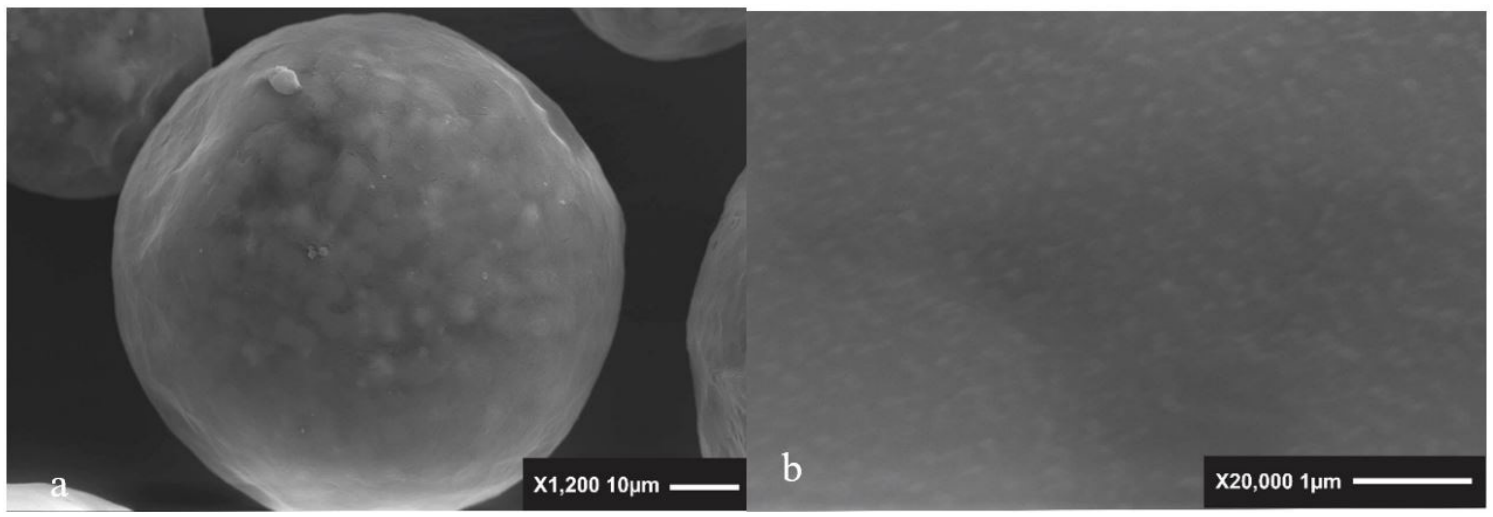

Figure 1. Scanning electron micrographs of the P(MMA-co-DVB)-M core: (a) x1,200 and (b) x20,000.

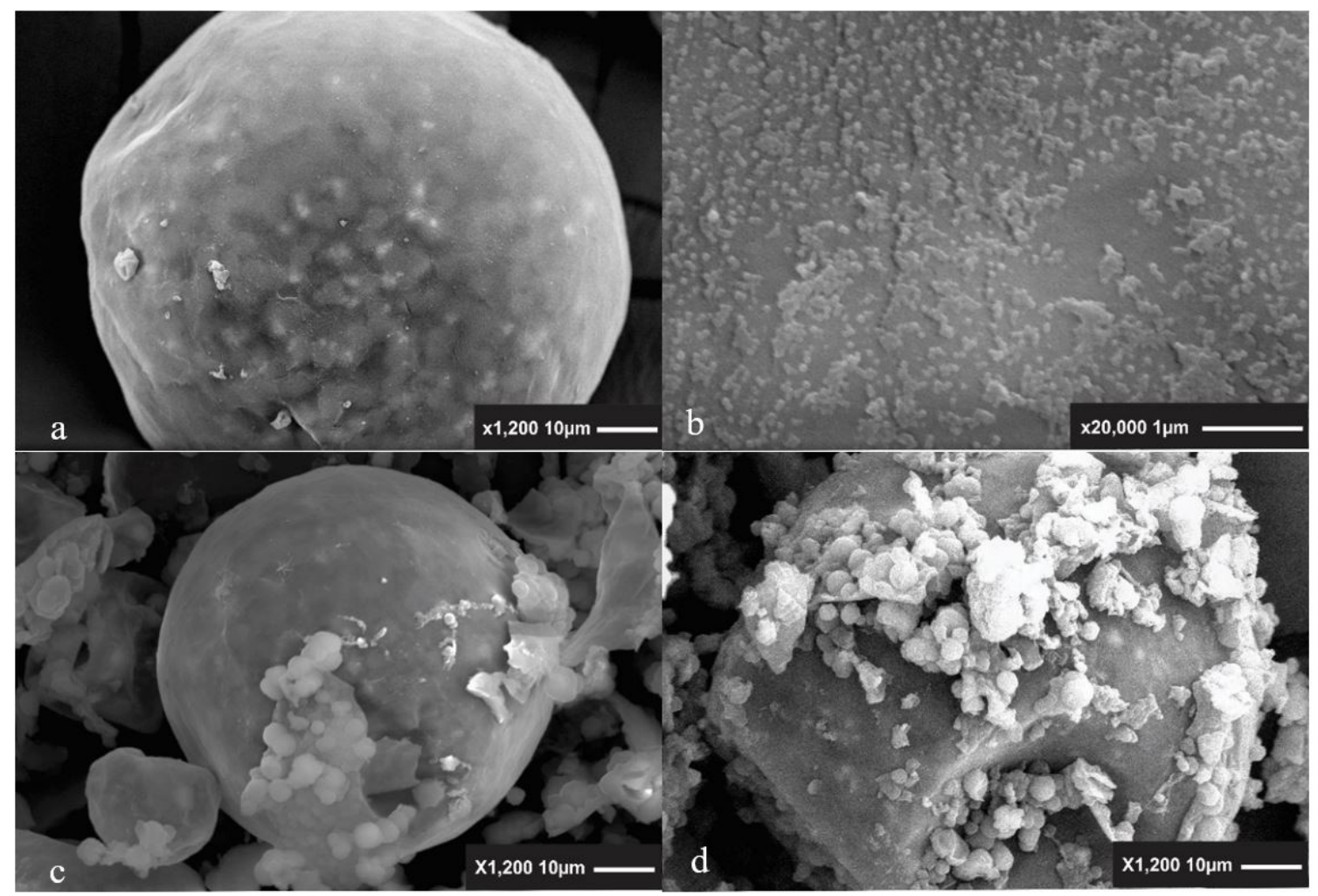

Figure 2. Scanning electron micrographs of the core shells synthesized with different swelling times: (a) and (b) 1 h, (c) 12 h, and (d) 24 h. 
Figure 2 also shows micrographs of the core-shells synthesized with different swelling times: $1 \mathrm{~h}$ (Figure $2 \mathrm{a}$ and $2 \mathrm{~b}$ ), $12 \mathrm{~h}$ (Figure 2c) and $24 \mathrm{~h}$ (Figure 2d). The increase of swelling time (12 and 24 hours) caused fracturing of the materials. During swelling, the core was under strong mechanical agitation for long periods, sufficient to cause collapse of the system. The core-shell synthesized after swelling for $1 \mathrm{~h}$ has a slightly rougher surface compared to the core (Figure 1b). This indicates that the shell monomers were adsorbed and polymerized on the core surface.

The electron micrographs of core-shells synthesized with different amounts of SDS and with different seed: monomer ratios of the shell are shown in Figure 3.
The surfaces of the core shells are compared with magnification of 20,000 $\mathrm{x}$ in Figure $2 \mathrm{~b}$ (WSDS), Figure $3 \mathrm{~b}$ (BCMC) and Figures 3d and 3f(ACMC 1:5 and ACMC 1:10, respectively). There is a subtle difference between them, where nanostructures can be observed adhered to the microspheres. These nanostructures tended to swell, forming a roughened film, with the increase of SDS content. The function of the surfactant is to decrease surface tension and monomer diffusion and prevent coalescence. Thus, the introduction of surfactant in the synthesis of core-shells caused greater concentration of monomer in the seed stage, but not in the aqueous phase, acting to reduce the amount of monomer dissolved in this phase. The appearance of the coatings was also different

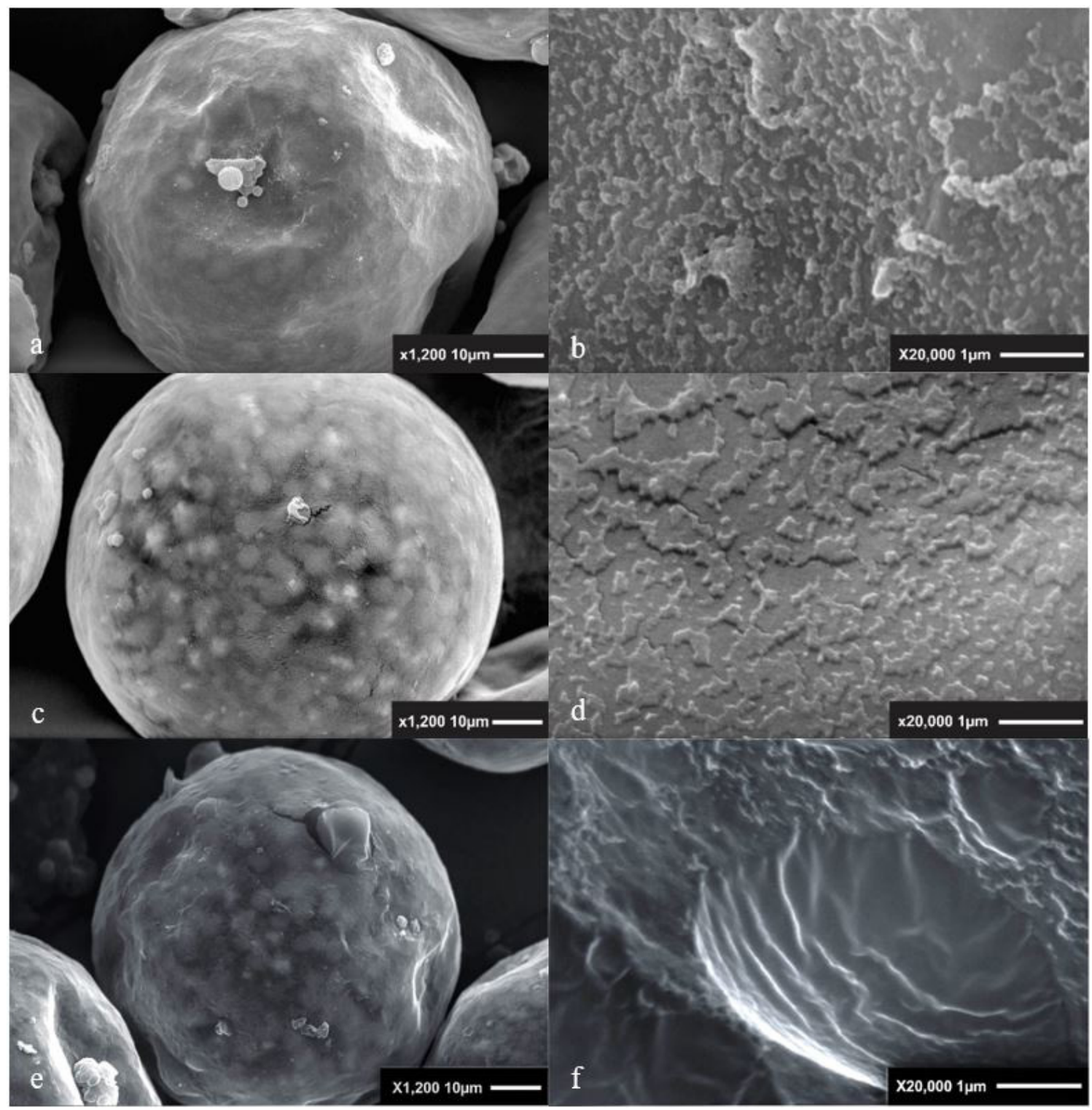

Figure 3. Scanning electron micrographs of the core shells: (a) and (b) sodium dodecyl sulfate below the critical micelle concentration, with seed mass ratios of: $\mathrm{OP}=1: 5$ (BCMC 1:5); (c) and (d) sodium dodecyl sulfate above the critical micelle concentration, with seed mass ratios of monomers - 1:5 (ACMC 1:5); (e) and (f) sodium dodecyl sulfate above the critical micelle mass ratios of seeds in shell monomers - 1:10 (ACMC 1:10). 
depending on the critical micelle concentration (CMC) of SDS. Comparing Figures $3 \mathrm{~b}$ and $3 \mathrm{~d}$ (BCMC and ACMC, respectively), the images suggest a coating replete with small points in BCMC and small plates attached in ACMC. The increase of SDS above the CMC led to formation of a thin film on the microspheres, probably due to the existence of a large number of micelles arranged in solution and the lower surface tension in the reaction system.

The literature indicates that when the concentration of SDS is below the CMC $\left(8.32 \times 10^{-3} \mathrm{~mol} / \mathrm{L}\right)$, the secondary nucleation is minimized ${ }^{[20]}$. This effect was not observed in any of the core-shells synthesized with different SDS concentrations. In both cases, the core-shells were well dispersed throughout the sample. This was possible because we performed a swelling test in a beaker before the synthesis, to limit the quantity of monomers in the system and prevent the polymerization from occurring outside the area of the seeds.

Figure $3 \mathrm{c}$ and Figure $3 \mathrm{e}$ show the SEM micrographs of core shells, with SDS above the CMC and different mass ratios of seeds (ACMC 1:5 and ACMC 1:10) and their respective surfaces (Figures $3 \mathrm{~d}$ and $3 \mathrm{f}$ ) for comparative purposes. In both core-shells, the surfaces are smooth, like plates attached to the surface. There is a report in the literature ${ }^{[1]}$ that when synthesis involves purification and drying, the result is enclosures without pores. This is due to the occurrence of heterogeneous nucleation in this polymerization system, so the molecules of the shell polymers are produced directly on the surface of the core. The ACMC core-shell with ratio of 1:10 (Figures 3e and 3f) has small bubbles on the shell surface and its coating appears to be more homogeneous than the ACMC core shell with ACMC 1:5 ratio (Figures $3 c$ and $3 d$ ). The uptake of the shell monomers in all the systems studied resulted in rough and thin film on the surface of the cores.

Figure 4 shows the results of particle size determination of the core-shell. As can be seen in the study of different swelling times (Figure 4a), the core-shell with $1 \mathrm{~h}$ of swelling had particle size range shifted to larger values. This is strong evidence that core microspheres were swollen and the polymerization of GMA/DVB took place to form the shell. Similar results have been found by other researchers ${ }^{[1,7]}$. In syntheses where the swelling time was longer, the displacement of the particle size was toward smaller sizes
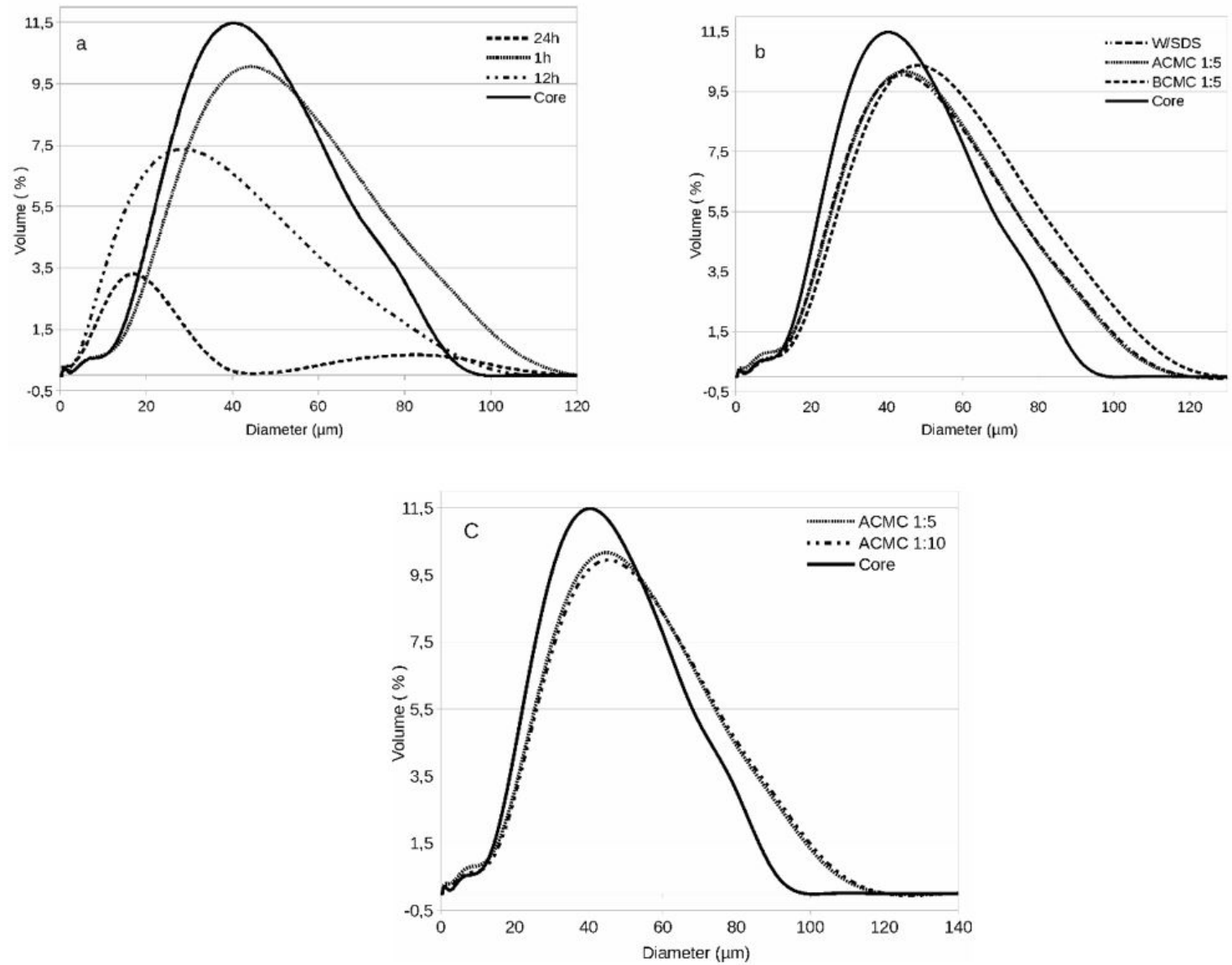

Figure 4. Size and size distribution of the of the P(MMA-co-DVB)-M core and core-shells (a) swelling for different times: $1 \mathrm{~h}, 12 \mathrm{~h}$ and $24 \mathrm{~h}$; (b) core-shell particles with different additions of surfactant: without sodium dodecyl sulfate (WSDS), sodium dodecyl sulfate below critical micelle concentration (BCMC), and sodium dodecyl sulfate above critical micelle concentration (ACMC) (mass ratios of seeds in shell monomers 1:5) and (c) core-shell particles with sodium dodecyl sulfate above critical micelle concentration and different mass ratios of seeds in shell monomers of 1:5 (ACMC 1:5) and 1:10 (ACMC 1:10) (obtained by dynamic light scattering). 
for the core, showing that these reactions caused fracture of the microspheres, confirming the results observed the SEM images (Figure 2). Comparison of the core and core-shells showed an upward shift of the size range in all second polymerization systems (Figures $4 \mathrm{~b}$ and $4 \mathrm{c}$ ). These results also show that increasing the monomer concentration in the shell formation from 1:5 to 1:10 (ACMC) (Figure 4c) did not influence the particle size displacement. Similar results have also been reported by ${ }^{[21,22]}$. It is known that crosslinked polymers have limited swelling degree. It is possible that this characteristic influences the evolution of the particle size of the core-shell. Another limitation to the evolution of the core-shell particle size is the size of the core. One of the biggest challenges of synthesizing core-shells is related to control to assure uniform coating thickness ${ }^{[1]}$.

The results of saturation magnetization of the synthesized core-shells with different concentrations of surfactant are shown in Figure 5a and with different shell monomer ratios in Figure 5b. At this stage, all the core shells showed good response to the magnetic field (7.3-6.8 emu/g) and remanent magnetization $\left(\mathrm{M}_{\mathrm{r}}\right.$ close to zero, indicating superparamagnetic behavior. The saturation magnetization also showed values below the core $\mathrm{M}_{\mathrm{s}}$ value $(7.5 \mathrm{emu} / \mathrm{g})$. The small differences in the results indicate possible loss of the magnetic material adsorbed during the second polymerization. Another possibility for the reduction of the core shell $\mathrm{M}_{\mathrm{s}}$ value is the presence of the polymer shell. Since this result is given in terms of mass, weight increase of the samples due to the incorporation of the $\mathrm{P}(\mathrm{GMA}-\mathrm{co}-\mathrm{DVB})$ to the $\mathrm{P}(\mathrm{MMA}-\mathrm{co}-\mathrm{DVB})-\mathrm{M}$ core can also be considered. According to the literature, these results would enable use of these materials as ion-exchange resins with magnetic properties and $\mathrm{M}_{\mathrm{s}}$ close to $8.0 \mathrm{emu} / \mathrm{g}$, would be excellent to use these microspheres in catalytic processes as well ${ }^{[23,24]}$.

The FTIR results obtained are shown in Figure 6. The axial asymmetrical deformation of the epoxide ring appears in the region of $906 \mathrm{~cm}^{-1}$. A report in the literature ${ }^{[25]}$ about the ATR-FTIR technique indicates that besides the analysis of
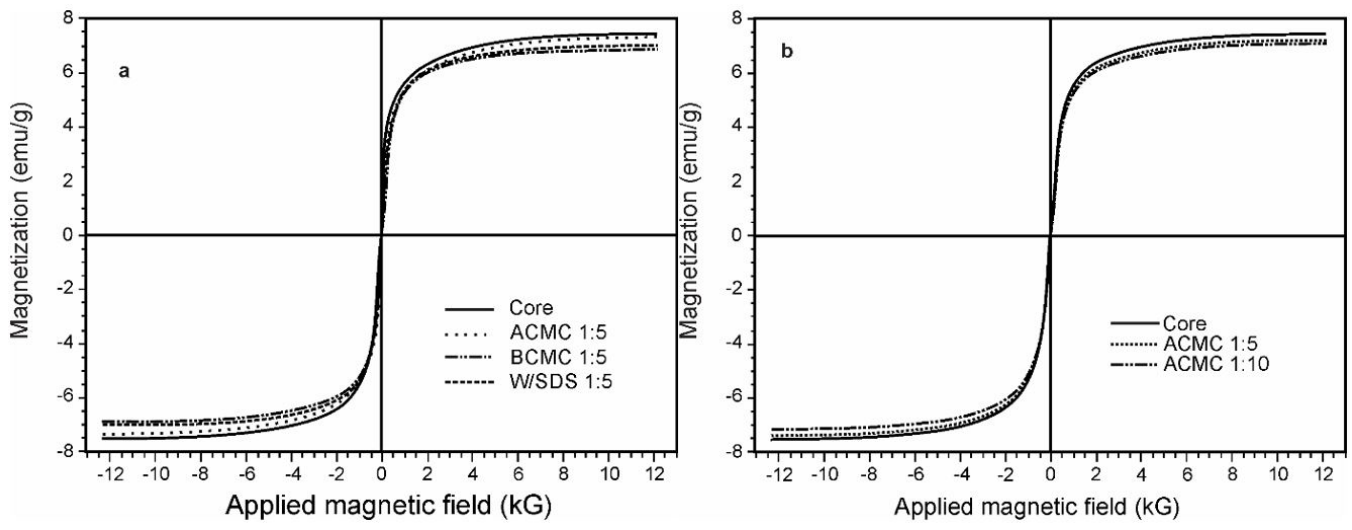

Figure 5. Saturation magnetization curves of the of the P(MMA-co-DVB)-M core and core shells obtained: (a) core-shell particles with different additions of surfactant: without sodium dodecyl sulfate (WSDS), sodium dodecyl sulfate below critical micelle concentration (BCMC), and sodium dodecyl sulfate above critical micelle concentration (ACMC) (mass ratios of seeds in shell monomers OP = 1:5) and (b) core-shell particles with sodium dodecyl sulfate above critical micelle concentration and different mass ratios of seeds in shell monomers of 1:5 (ACMC 1:5) and 1:10 (ACMC 1:10).

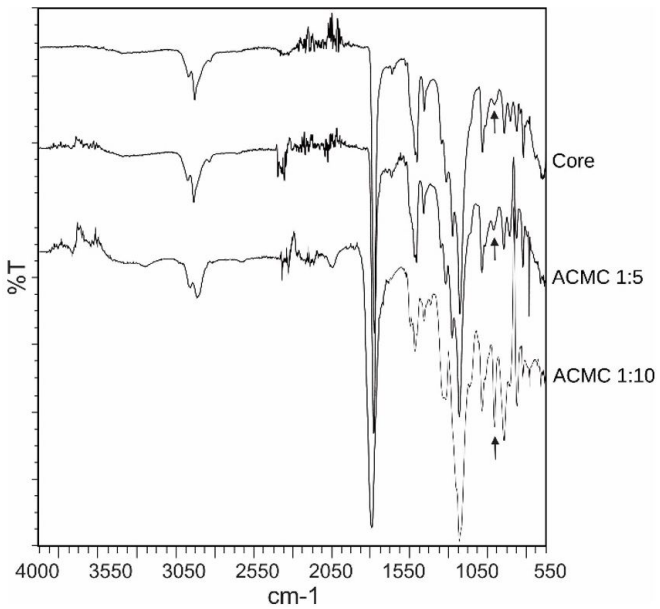

Figure 6. FTIR spectra of the P(MMA-co-DVB)-M core and core-shell particles with sodium dodecyl sulfate above critical micelle concentration and different mass ratios of seeds in shell monomers of 1:5 (ACMC 1:5) and 1:10 (ACMC 1:10). 


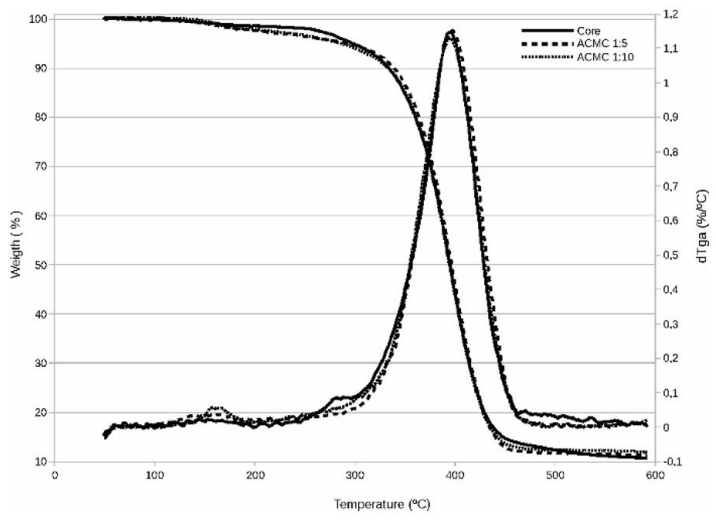

Figure 7. TG and DTG curves of the P(MMA-co-DVB)-M core and core-shell particles with sodium dodecyl sulfate above critical micelle concentration and different mass ratios of seeds in shell monomers of 1:5 (ACMC 1:5) and 1:10 (ACMC 1:10).

the interaction of matter with electromagnetic radiation in the infrared range, in many cases the technique can perform quantitative analysis, since the response to the signal obtained by FTIR spectra can be related to the concentration of analyte in the sample. In the sample ACMC1:10, this band is more intense than in sample ACMC 1:5, so it is possible that the adsorption of GMA in this synthesis was more significant.

Figure 7 shows the thermal degradation curves of the core-shells synthesized with different concentrations of shell monomers. All the samples also showed a small weight loss between $100-200^{\circ} \mathrm{C}$, attributed to the presence of GMA trace amounts in the samples (their degradation temperature is around $180^{\circ} \mathrm{C}$ ). Above this temperature, only one thermal degradation stage $\left(T_{\text {ONSET }}=300{ }^{\circ} \mathrm{C}\right)$ occurred for the core-shell samples, indicating there was no change in the degradation profile according to the shell formation method. The results also show no significant change in $\mathrm{T}_{M A X}$ values (about $397^{\circ} \mathrm{C}$ ) of the core shells compared to the core. This result can be explained by the fact the shell is a thin layer that probably did not affect the thermal degradation of the samples at this stage.

\section{Conclusions}

It was possible to synthesize polymeric microspheres with core-shell morphology based on (P(MMA-co-DVB)-M) constituting the core and $\mathrm{P}(\mathrm{GMA}-\mathrm{co}-\mathrm{DVB})$ composing the shell. The core-shells obtained with stirring speed of $600 \mathrm{rpm}$ had good magnetic properties $\left(\mathrm{M}_{\mathrm{s}} \approx 7.1 \mathrm{emu} / \mathrm{g}\right)$ and were free of hysteresis. The scanning electron microscopic images were efficient to show the formation of the shell on the polymeric core. The light scattering analysis showed the displacement of particle size distribution to larger sizes $(5-90 \mu \mathrm{m}$ (core) to $5-120 \mu \mathrm{m}$ (core-shell)). The FTIR spectra also showed the incorporation of glycidyl methacrylate, corroborating the other results and confirming the formation of magnetic polymeric microspheres with core-shell morphology. Finally, there was no change in degradation profile in the core-shells according to the TG and DTG curves.

\section{Acknowledgements}

The authors thank Coordenação de Aperfeiçoamento de Pessoal do Nível Superior (CAPES) (Edital 04/CII-2008, REDE NANOBIOTEC - BRASIL) for financial support via the doctoral scholarship awarded through the project called "Nanobiotechnology for the development of polymer materials for applications in health and the environment", Migquimica for AIBN donation, Nitriflex for donating the monomers, and Laboratório de Engenharia de Polimerização (ENGEPOL) of Instituto Alberto Luiz Coimbra de Pós-Graduação e Pesquisa de Engenharia (COPPE-UFRJ) for dynamic light scattering analysis.

\section{References}

1. Ghosh Chaudhuri, R., \& Paria, S. (2012). Core/shell nanoparticles: classes, properties, synthesis mechanisms, characterization and applications. Chemical Reviews, 112(4), 2373-2433. http:// dx.doi.org/10.1021/cr100449n. PMid:22204603.

2. Pei, X., Zhai, K., Tan, Y., Xu, K., Lu, C., Wang, P., Wang, T., Chen, C., Tao, Y., Dai, L., \& Li, H. (2017). Synthesis of magnetite starch-polystyrene core-shell nanoparticles via seeded emulsion polymerization without stabilizer. Polymer, 108, 78-86. http://dx.doi.org/10.1016/j.polymer.2016.11.035.

3. Lu, M., Bai, S., Yang, K., \& Sun, Y. (2007). Synthesis and characterization of magnetic polymer microspheres with a core-shell structure. China Particuology, 5(1-2), 180-185. http://dx.doi.org/10.1016/j.cpart.2007.01.012.

4. Pinto, M. C. C., Freire, D. M. G., \& Pinto, J. C. (2014). Influence of the morphology of core-shell supports on the immobilization of lipase B from candida antarctica. Molecules (Basel, Switzerland), 19(8), 12509-12530. http://dx.doi. org/10.3390/molecules 190812509. PMid:25153868.

5. Besteti, M. D., Cunha, A. G., Freire, D. M. G., \& Pinto, J. C. (2014). Core/shell polymer particles by semibatch combined suspension/emulsion polymerizations for enzyme immobilization. Macromolecular Materials and Engineering, 299(2), 135-143. http://dx.doi.org/10.1002/mame.201300023.

6. Ribeiro, L. F. B., Gonçalves, O. H., Marangoni, C., Motz, G., \& Machado, R. A. F. (2017). Chemical resistance of core-shell particles (PS/PMMA) polymerized by seeded suspension. Polimeros: Ciência e Tecnologia, 27(3), 225-229. http://dx.doi. org/10.1590/0104-1428.13216.

7. Formiga, W. J. F., Mello, I. L., Costa, M. A. S., Silva, M. R., \& Oliveira, M. G. (2013). Microesferas poliméricas magnéticas à base de estireno e divinilbenzeno com morfologia casca e núcleo. Polímeros: Ciência e Tecnologia, 23(2), 262-269. http://dx.doi.org/10.4322/polimeros.2013.075.

8. Horák, D., Hlídková, H., Hiraoui, M., Taverna, M., Proks, V., Mázl Chánová, E., Smadja, C., \& Kučerová, Z. (2014). Monodisperse carboxyl-functionalized poly(ethylene glycol)coated magnetic poly(glycidyl methacrylate) microspheres: Application to the immunocapture of b-amyloid peptides. Macromolecular Bioscience, 14(11), 1590-1599. http://dx.doi. org/10.1002/mabi.201400249. PMid:25142028.

9. Chung, T. H., Chang, J. Y., \& Lee, W. C. (2009). Application of magnetic poly(styrene-glycidyl methacrylate) microspheres for immunomagnetic separation of bone marrow cells. Journal of Magnetism and Magnetic Materials, 321(10), 1635-1638. http://dx.doi.org/10.1016/j.jmmm.2009.02.103.

10. Horak D., Svobodova Z., Autebert J., Coudert B., Plichta Z., Kralovec K., Bilkova Z., \& Viovy J. L. (2012). Albumincoated monodisperse magnetic poly(glycidyl methacrylate) microspheres with immobilized antibodies: application to 
the capture of epithelial cancer cells. Journal of Biomedical Materials Research Part A, 101A(1):22-32. http://dx.doi. org/10.1002/jbm.a.34297.

11. Sun, X., Yang, L., Xing, H., Zhao, J., Li, X., Huang, Y., \& Liu, H. (2014). High capacity adsorption of Cr(VI) from aqueous solution using polyethylenimine-functionalized poly(glycidyl methacrylate) microspheres. Colloids and Surfaces. A, Physicochemical and Engineering Aspects, 457, 160-168. http://dx.doi.org/10.1016/j.colsurfa.2014.05.061.

12. Sandić, Z. D., Žunić, M., Maksin, D. D., Milutinović-Nikolić, A. D., Popović, A. R., Jovanović, D. M., \& Nastasović, A. B. (2014). Glycidyl methacrylate macroporous copolymer grafted with diethylene triamine as sorbent for reactive black 5 . Hemijska Industrija, 68(6), 685-699. http://dx.doi.org/10.2298/ HEMIND140127023S.

13. Castanharo, J. A., Ferreira, I. L. M., Silva, M. R., Costa, G. M., Oliveira, M. G., \& Costa, M. A. S. (2015). Microesferas magnéticas à base de poli(metacrilato de metila-co-divinilbenzeno) obtidas por polimerização em suspensão. Polímeros: Ciência e Tecnologia, 25(2), 192-199. http://dx.doi.org/10.1590/01041428.1666.

14. Gonçalves, O. H., Machado, R. A., Araújo, P. H., \& Asua, J. M. (2009). Secondary particle formation in seeded suspension polymerization. Polymer, 50(2), 375-381. http://dx.doi. org/10.1016/j.polymer.2008.11.006.

15. Lin, W., Biegler, L. T., \& Jacobson, A. M. (2010). Modeling and optimization of a seeded suspension polymerization process. Chemical Engineering Science, 65(15), 4350-4362. http://dx.doi.org/10.1016/j.ces.2010.03.052.

16. Rabelo, D., \& Coutinho, F. M. B. (1994). Porous structure formation and swelling properties of styrene-divinylbenzene copolymers. European Polymer Journal, 30(6), 675-682. http:// dx.doi.org/10.1016/0014-3057(94)90115-5.

17. Belfer, S., Egozy, Y., \& Korngold, E. (1984). Resins containing extractants: morphology of polymers prepared by polymerization of vinyl monomers in the presence of uranium-selective extractants. Journal of Applied Polymer Science, 29(12), 3825-3836. http://dx.doi.org/10.1002/app.1984.070291216.
18. Heydarpoor, S., Abbasi, F., Jalili, K., \& Najafpour, M. (2015). Synthesis of core-shell PS/PMMA expandable particles via seeded suspension polymerization. Journal of Polymer Research, 22(8), 151-161. http://dx.doi.org/10.1007/s10965-015-0789-0.

19. Lenzi, M. K., Silva, F. M., Lima, E. L., \& Pinto, J. C. (2003). Semibatch styrene suspension polymerization processes. Journal of Applied Polymer Science, 89(11), 3031-3038. http:// dx.doi.org/10.1002/app.12443.

20. Daigle, J. C., \& Claverie, J. P. (2008). A simple method for forming hybrid core-shell nanoparticles suspended in water. Journal of Nanomaterials, 1, 1-8. http://dx.doi.org/10.1155/2008/609184.

21. Liu, X., Fan, X. D., Tang, M. F., \& Nie, Y. (2008). Synthesis and Characterization of Core-Shell Acrylate Based Latex and Study of Its Reactive Blends. International Journal of Molecular Sciences, 9(3), 342-354. http://dx.doi.org/10.3390/ ijms9030342. PMid:19325753.

22. Lan, F., Liu, K. X., Jiang, M., Zeng, X. B., Wu, Y., \& Gu, Z. W. (2011). Facile synthesis of monodisperse superparamagnetic $\mathrm{Fe}_{3} \mathrm{O}_{4} / \mathrm{PMMA}$ composite nanospheres with high magnetization. Nanotechnology, 22(22), 225604-225610. http://dx.doi. org/10.1088/0957-4484/22/22/225604. PMid:21454944.

23. Lee, Y., Rho, J., \& Jung, B. (2003). Preparation of magnetic ion-exchange resins by the suspension polymerization of styrene with magnetite. Journal of Applied Polymer Science, 89(8), 2058-2067. http://dx.doi.org/10.1002/app.12365.

24. Yuan, D., Zhang, Q., \& Dou, J. (2010). Supported nanosized palladium on superparamagnetic composite microspheres as an efficient catalyst for Heck reaction. Catalysis Communications, 11(7), 606-610. http://dx.doi.org/10.1016/j.catcom.2010.01.005.

25. Conceição, V. N., Souza, L. M., Merlo, B. B., Filgueiras, P. R., Poppi, R. J., \& Romã, W. (2014). Estudo do teste de Scott via técnicas espectroscópicas: um método alternativo para diferenciar cloridrato de cocaína e seus adulterantes. Quimica Nova, 37, 1538-1544. http://dx.doi.org/10.5935/0100-4042.20140240.

Received: Oct. 27, 2017

Revised: Apr. 06, 2018

Accepted: June 05, 2018 